\title{
A RELAÇÃO ENTRE ESTADO DE DIREITO E DEMOCRACIA SEGUNDO HABERMAS: A RELEVÂNCIA DA MEDIAÇÃO JURÍDICA
}

\author{
F. Jozivan Guedes de L. ${ }^{1}$
}

\begin{abstract}
Resumo
O artigo tenciona demonstrar a vinculação entre Estado de direito e democracia a partir das considerações de Habermas destacando a relevância da mediação do direito no que diz respeito à articulação entre autonomia privada e autonomia política, soberania popular e direitos humanos. Metodologicamente, Habermas propõe a vinculação supramencionada a partir de três momentos: (i) complementaridade entre direito positivo e moral; (ii) a mediação entre soberania popular e direitos humanos; (iii) relação entre autonomia privada e autonomia pública. A hipótese central é que a desagregação entre autonomia privada e autonomia pública provoca uma ruptura no próprio Estado de direito democrático.
\end{abstract}

Palavras-chave: Estado de direito. Democracia. Direito. Autonomia. Habermas.

\section{THE RELATIONSHIP BETWEEN STATE OF LAW AND DEMOCRACY ACCORDING TO HABERMAS: THE RELEVANCE OF LEGAL MEDIATION}

\begin{abstract}
This paper aims to demonstrate the relationship between State of Law and democracy based on Habermas' considerations highlighting the relevance of the legal mediation regarding the articulation between private and political autonomy, popular sovereignty and human rights. Methodologically, Habermas articulates that biding from three moments: (i) the complementarity between positive law and moral; (ii) the mediation between popular sovereignty and human rights (iii) the relation between private and public autonomy. The hypothesis central is that the rupture between private and public autonomy causes a break in the democratic State of law.
\end{abstract}

Keywords: State of Law. Democracy. Law. Autonomy. Habermas.

\section{Introdução}

No mundo acadêmico é comum, segundo Habermas (2018, p. 419), considerar em termos metodológicos Estado de direito e democracia objetos de investigação pertencentes a disciplinas distintas, de modo que a democracia seria objeto da ciência política, e o Estado de direito objeto de estudos da jurisprudência. $O$ direito faria um estudo mais normativo e a ciência política um estudo mais empírico. A filosofia não se limita a tal divisão e cumpre a ela o papel de apresentar as justificativas plausíveis de uma vinculação entre ambos os objetos.

Assim, Habermas encaminha a tentativa de um nexo interno entre Estado de direito e democracia a partir da mediação jurídica no escopo de sua ética discursiva para dizer que o Estado de direito não está centrado exclusivamente na dependência do direito positivado, mas em procedimentos jurídicos com vistas ao exercício da autonomia política por parte de cidadãos

\footnotetext{
1 Professor do Programa de Pós-Graduação em Filosofia-UFPI. Professor do Programa de Pós-Graduação em Ciência Política-UFPI. Doutor em Filosofia-PUCRS. Orcid: https://orcid.org/0000-0003-4483-8393. E-mail: jozivan2008guedes@gmail.com.
} 
e cidadãs como sendo um elemento necessário e, de modo simultâneo, dependente da democracia.

A democracia precisa do Estado de direito para manter-se firme institucional e constitucionalmente e, por sua vez, o Estado direito precisa da democracia para legitimar-se como garantidor da autonomia privada e da autonomia pública. $O$ direito tem função imprescindível na defesa e na garantia do vínculo entre soberania popular (autonomia pública) e direito humanos (autonomia privada), a ponto de tal desvinculação implicar a deterioração do próprio Estado de direito democrático. Nesse sentido, deve haver uma relação de complementaridade entre Estado de direito e democracia, e o direito tem papel fundamental nesse nexo.

Metodologicamente, Habermas propõe a vinculação supramencionada a partir de três momentos: (i) complementaridade entre direito positivo e moral; (ii) mediação entre soberania popular e direitos humanos; (iii) relação entre autonomia privada e autonomia pública.

\section{A complementaridade entre direito positivo e moral}

Habermas (2018, p. 420), pensa a relação entre direito e moral numa dupla perspectiva: num primeiro momento ressalta como a tradição moderna contratualista evidencia a necessidade de superação do positivismo demonstrando a imprescindibilidade de uma fundamentação moral do direito recorrendo à lei natural; num segundo momento, mostra a necessidade de ir além dessa fundamentação moral plasmada na lei natural, ampliando-a em direção à fundamentação discursiva da normatividade.

Quanto ao rechaço do positivismo dentro do jusnaturalismo contratualista, podemos encontrar no Leviatã de Hobbes uma primazia da lei natural da autodefesa como conservatio vitae e dever de autopreservação diante da lei positiva.

O direito de natureza, a que os autores geralmente chamam jus naturale, é a liberdade que cada homem possui de usar seu próprio poder, da maneira que quiser, para a preservação de sua própria natureza, ou seja, de sua vida; e consequentemente de fazer tudo aquilo que seu próprio julgamento e razão lhe indiquem como meios adequados a esse fim (HOBBES, 2003, cap. XIV).

A lei natural da autodefesa e da autopreservação jamais cessa no Estado civil, de modo que a lei positiva tem sua justificação normativa e sua razão de ser no cumprimento da lei natural. Nenhum Estado, nenhum soberano, nenhuma legalidade podem violar tal lei. Nesse sentido, penso que é um equívoco reduzir a proposta de Hobbes a um absolutismo. Se há algo

\begin{tabular}{|l|l|l|l|l|}
\hline Govista Qialectus & Ano 10 & n. 24 & Setembro - Dezembro 2021 & p. 67 - 78 \\
\hline
\end{tabular}


de absoluto em sua filosofia política é a inalienabilidade da lei natural da autopreservação. Inclusive o súdito está legitimado a desobedecer ao soberano caso tal direito natural esteja em apuros. $^{2}$

\begin{abstract}
Se o soberano ordenar a alguém (mesmo que justamente condenado) que se mate, se fira ou se mutile a si mesmo, ou que não resista aos que o atacarem, ou que se abstenha de usar os alimentos, o ar, os medicamentos, ou qualquer outra coisa sem a qual não poderá viver, esse alguém tem a liberdade de desobedecer. Se alguém for interrogado pelo soberano ou por sua autoridade, relativamente a um crime que cometeu, não é obrigado (a não ser que receba garantia de perdão) a confessá-lo, porque ninguém [...] pode ser obrigado por um pacto a recusar-se a si próprio) (HOBBES, 2003, cap. XXI).
\end{abstract}

Essa premissa da primazia da lei natural também é encontrada em Locke para quem o Estado civil, o Estado regido por leis positivas, é estabelecido como um remédio contra os inconvenientes do estado de natureza que, por ser destituído de justiça pública para fazer a mediação de conflitos, está na iminência de injustiças. Locke pensa que a função precípua do Estado civil fruto de um contrato é preservação da propriedade, e a propriedade não meramente num sentido estrito como propriedade privada como comumente se interpreta de modo equivocado, mas num sentido lato como preservação da vida, liberdade e bens (LOCKE, 2005, $\S 123)$.

O mandamento da razão no estado de natureza segundo o qual "ninguém pode prejudicar a outrem em sua vida, saúde, liberdade ou posses" (LOCKE, 2005, § 6) não pode ser jamais violado por qualquer governo civil, a ponto que o contrário disso legitima a resistência, o fim do Estado civil e o retorno ao estado de natureza até que se estabeleça um novo governo mediante um novo contrato (LOCKE, 2005, § 243). Desse modo, também em Locke há uma articulação fundamental entre direito e moral, moral entendida aqui como lei natural da razão.

Em Kant, essa relação se apresenta de modo mais emblemático haja vista a moral ser posta como condição fundamentadora do direito. A fonte normativa do direito não está nas legislações empíricas ou na moldura do próprio direito positivado, mas em algo externo a ele, a saber, na razão pura prática; de um modo mais claro, está na liberdade pensada como um conceito inato da razão, portanto, como um valor moral que serve de critério para discernir o que é justiça e o que é injustiça, pois "uma doutrina do direito meramente empírica é (como a cabeça de madeira na fábula de Fedro) uma cabeça que pode ser bela, mas infelizmente não tem cérebro" (KANT, 2014, n. 230).

\footnotetext{
${ }^{2}$ Noutro artigo já tratei de um modo mais sistemático da relação entre direito natural e direito positivo à luz do direito de resistência em Hobbes, Locke e Kant. Cf. GUEDES DE LIMA (2018). https://revistas.ufpi.br/index.php/pensando/article/view/7669/5015

\begin{tabular}{|l|l|l|l|l|}
\hline Q & Ano 10 & n. 24 & Setembro - Dezembro 2021 & p. 67 - 78
\end{tabular}
}


Ou seja, para Kant a moral é o cérebro que fundamenta o direito, e sem ela o direito é acéfalo. Há aqui uma primazia da lei natural da razão, uma logonomia, uma fundamentação de normas mediante a razão. Na mesma introdução à Metafísica dos Costumes lê-se: “pode-se, portanto, pensar numa legislação externa que contivesse somente leis positivas, mas então teria de proceder uma lei natural que fundamentasse a autoridade do legislador" (KANT, 2014, n. 224).

Para Habermas esse tipo de fundamentação a priori sem embasamento democrático e discursivo retira a autonomia do direito tornando-o inferior ou mesmo absorvido pela moral. Como afirma em Facticidade e Validade:

Para Hobbes, o direito positivo é, em última instância, o meio de organização do poder político; ao passo que, para Kant, ele continua tendo caráter essencialmente moral. [...]. Hobbes sacrifica a indisponibilidade do direito em favor de sua positividade, ao passo que, em Kant, o direito moral ou natural, deduzido a priori da razão prática, ocupa a tal ponto o lugar central, que o direito corre o risco de se desfazer em moral; falta pouco para o direito ser reduzido a um modo deficiente de moral (HABERMAS, 1997, p. 237). ${ }^{3}$

Habermas entende que o jusnaturalismo, uma fundamentação do direito a partir da lei natural da razão, é importante para rechaçar o positivismo jurídico, mas é necessário recriar um espaço de fortalecimento do direito que seja plasmado nas relações intersubjetivas e no interior de uma discursividade. Assim, a moral kantiana é redimensionada para uma ética do discurso, e o vínculo entre direito e moral é refeito no escopo democrático, e o direito passa a ser um medium entre facticidade e validade.

A explicação do direito natural se apoia em imagens metafísicas do mundo que já não podem mais convencer universalmente em sociedades pluralistas. Em contraposição a isso, a teoria do discurso atribui ao próprio procedimento da formação democrática da opinião e da vontade a força geradora de legitimidade (HABERMAS, 2014a, p. 99).

A abordagem da teoria do discurso tem a vantagem de poder especificar os pressupostos da comunicação que devem ser satisfeitos nas diferentes formas de argumentação e nas negociações, se os resultados de tais discursos devem ter para si a suposição de razoabilidade (HABERMAS, 2014b, p. 75).

O direito tem um papel nuclear nesse redimensionamento no que concerne à institucionalização dos procedimentos discursivos e da garantia de participação como sendo um esteio de democracias devidamente estáveis.

${ }^{3}$ Na versão alemã de Faktzität und Geltung, lê-se: „Hobbes opfert die Unverfügbarkeit des Rechts seiner Positivität auf, bei Kant gewinnt das aus praktischer Vernunft apriori abgeleitete natürliche oder moralische Recht so sehr die Oberhand daß Recht in Moral aufzugehen droht: Recht wird beinahe zu einem defizienten Modus der Moral herabgestuft.“ (HABERMAS, 1994, p. 590-591).

\begin{tabular}{|l|l|l|l|l|}
\hline Govista Qialeatus & Ano 10 & n. 24 & Setembro - Dezembro 2021 & p. 67 - 78 \\
\hline
\end{tabular}


Apesar da discordância de Habermas em relação ao modo como Kant trata a dependência moral do direito, há um aspecto que ele considera interessante na abordagem kantiana, a saber, o modo como foi processada a relação entre direito, coerção e liberdade.

\footnotetext{
Desde Locke, Rousseau e Kant, não apenas na filosofia, mas também pouco a pouco na realidade constitucional das sociedades ocidentais, foi se estabelecendo um conceito de direito que leva em conta simultaneamente tanto a positividade do direito coercitivo quanto seu caráter de fiador da liberdade (HABERMAS, 2018, p. 420).
}

Cumpre ao Estado de direito a necessidade de demonstrar a legitimidade do uso da coerção sobre os indivíduos, a ponto que o contrário disso resulta em uso arbitrário e violento da força e do poder: "no modo de validade do direito, a facticidade da imposição do direito pelo Estado se entrelaça com a legitimidade da força fundamentadora de um procedimento de positivação do direito que tem a pretensão de ser racional por estar fundamentado na liberdade" (HABERMAS, 2018, p. 421).

Esse entrelaçamento entre a facticidade da coerção e a sua necessidade de validade veio da Doutrina do Direito de Kant ao considerar que uma coerção só é legítima se for usada para garantir o exercício da liberdade, e desse modo foram colocadas numa mesma base a legalidade e a legitimidade. "É justa toda ação mediante a qual ou segundo cuja máxima a liberdade do arbítrio de cada um pode coexistir com a liberdade de qualquer um segundo uma lei universal etc.” (KANT, 2014, n. 230).

Uma ação injusta implica a privação da liberdade e, por isso, requer a coerção do direito a fim de que a liberdade seja restabelecida. A legitimidade da coerção está na garantia da liberdade, e a fruição da liberdade está na sua garantia pela coerção jurídica quando ela estiver sob risco, cerceamento e ameaça: “da mesma forma que a coerção 'legítima' só é possível com base na liberdade, a liberdade 'legítima' exige por si mesma a coerção para que possa existir" (MARCUSE, 1972, p. 96).

Habermas amplia o sentido de legitimidade em vista da ética do discurso e da sua vinculação política com a democracia. Ele fala em "conceito político" de legitimação que tem sentido apenas quando relacionado ao Estado de direito democrático (cf. HABERMAS, 2003, p. 67). Não é mais necessário pensar numa hierarquia em que o direito tem na moral sua fonte de normatividade, mas se parte do pressuposto de uma relação de complementaridade entre direito e moral, sendo que a legitimidade das normas jurídicas não deriva mais de uma razão, mas de razões discutidas e consensuadas nas interações, haja vista o pluralismo das sociedades. “A prática legislativa de justificar o direito depende de uma rede ramificada de discursos e negociações - e não apenas de discursos morais" (HABERMAS, 2018, p. 425).

\begin{tabular}{|l|l|l|l|l|}
\hline Rovista Dialectus & Ano 10 & n. 24 & Setembro - Dezembro 2021 & p. 67 - 78
\end{tabular}


Essa relação de complementaridade entre direito e moral - que não deve ser mais de subordinação - requer a articulação simétrica entre autonomia privada e autonomia pública, de modo que o cidadão destinatário das leis seja simultaneamente o autor das leis - e aqui subjaz a ideia kantiana de autonomia segundo a qual os indivíduos cumprem aquelas normas morais às quais eles são os autores. No caso da dimensão jurídica, "as pessoas de direito só podem ser autônomas à medida que, no exercício de seus direitos de cidadãos, possam se compreender como autores daqueles direitos aos quais devem obedecer" (HABERMAS, 2018, p. 426).

A complementaridade entre direito e moral significa que o direito garante pela lei positiva e mediante os procedimentos jurídicos e democráticos a autonomia privada e pública das pessoas e, por sua vez, a moral discursiva garante que o direito seja sustentado e alimentado por normatividades oriundas de processos democráticos de discussão acerca da validade das leis.

\section{A mediação entre soberania popular e direitos humanos ${ }^{4}$}

Um outro ponto necessário para a vinculação entre Estado de direito e democracia - o que se propõe neste artigo - se dá na indispensabilidade do nexo entre soberania popular e direitos humanos a partir da mediação do direito. A soberania popular concerne à autonomia pública dos cidadãos e os direitos humanos dizem respeito à garantia dos direitos fundamentais e da autonomia privada sob o império das leis.

O princípio da soberania popular se expressa nos direitos de comunicação e de participação que asseguram a autonomia pública dos cidadãos; o império das leis se expressa naqueles direitos fundamentais clássicos que garantem a autonomia privada dos cidadãos sociais. O direito legitima-se desse modo como um meio para a garantia igual da autonomia privada e da autonomia política (HABERMAS, 2018, p. 426).

No escopo da filosofia política ainda não foi possível o equilíbrio entre soberania popular e direitos humanos e, desse modo, persiste uma tensão entre liberdade dos antigos e liberdade dos modernos, isto é, uma polarização entre comunidade e indivíduo. Benjamin Constant identificou do seguinte modo os perigos dessa polarização:

O perigo da liberdade antiga era que, atentos unicamente a garantir a participação no poder social, os homens não faziam muito bom uso dos direitos e gozos individuais. O perigo da liberdade moderna é o de que, absorvida pelo gozo de nossa independência privada e pela busca de nossos interesses particulares, renunciemos

4 Numa outra ocasião, eu e o professor Delamar abordamos os direitos humanos em Habermas a partir de uma perspectiva transnacional e cosmopolita. Cf. GUEDES DE LIMA; VOLPATO DUTRA, 2020. https://periodicos.ufrn.br/principios/article/view/20213

\begin{tabular}{|l|l|l|l|l|}
\hline Q Rovista Dialectus & Ano 10 & n. 24 & Setembro - Dezembro 2021 & p. $67-78$ \\
\hline
\end{tabular}


Essa tensão foi vislumbrada no embate entre republicanismo e liberalismo, o primeiro enfatizando a dimensão da pólis assegurando a tese segundo a qual o indivíduo encontra seu sentido em comunidade, o segundo realçando a dimensão individual e a sua necessária tutela pelo Estado de direito.

O republicanismo, que remonta a Aristóteles e ao humanismo político do Renascimento, sempre concedeu primazia à autonomia pública em relação às liberdades pré-políticas das pessoas privadas. O liberalismo, que remonta a Locke, sobrecarregou o perigo das maiorias tirânicas e postulou uma prioridade dos direitos humanos (HABERMAS, 2018, p. 426).

Habermas (2018, p. 427) diz que Rousseau e Kant tencionaram em suas filosofias equilibrar soberania popular e direitos humanos, mas não conseguiram, sendo que Rousseau fortaleceu o republicanismo da soberania popular e Kant, por sua vez, o liberalismo dos direitos humanos. Ele defende que a teoria do discurso obteve tal êxito à medida que institucionalizou as formas de participação e comunicação a partir da premissa dos direitos humanos, tornando-as assim complementares em vez de discrepantes.

O vínculo interno que se almeja entre os direitos humanos e a soberania popular consiste, então, na condição de que a exigência para institucionalizar pelo direito uma prática cidadã de uso público das liberdades comunicativas seja cumprida justamente pelos próprios direitos humanos. Os direitos humanos, que tornam possível o exercício da soberania popular, não podem se impor de fora como uma resistência a essa prática (HABERMAS, 2018, p. 428).

Do ponto de vista mais prático possível, essa vinculação entre soberania popular e direitos humanos, sob a medição do direito, incide na relação entre autonomia privada e autonomia pública, de modo que emerge a figura do cidadão como destinatário e coautor das normas. É papel precípuo do direito defender positivamente (por meio da lei) ambas as autonomias e, desse modo, fazer a mediação da vinculação interna entre Estado de direito e democracia.

\section{A relação entre autonomia privada e autonomia pública}

Habermas (2018, p. 429) defende a ideia segundo a qual os direitos humanos, mesmo que bem fundamentados moralmente, não podem ser impostos, haja vista a complexidade de culturas plurais com seus valores diferentes e mesmo conflituosos - o que 
Rawls chama de "fato do pluralismo razoável"5 . Isso é um dado conjuntural do qual não se pode fugir ou desprezar da reflexão. Não há uma concepção de bem, uma metafísica ou religião absoluta que dite o modus vivendi e as ações dos sujeitos de modo uniforme. É necessário entrar em negociação, dissensos e consensos acerca da normatividade. Esse é o imperativo dos nossos tempos.

Isso implica que o direito não pode ser diluído na moral. Em democracias estáveis ele deve ser autônomo e garantir via institucionalização de regras positivadas a estabilidade democrática e a contínua legalidade e legitimidade do Estado de direito. Isso influencia na integração entre autonomia privada e autonomia pública de modo que "a ideia de autonomia jurídica dos cidadãos exige que os destinatários do direito possam ao mesmo tempo se entender como seus autores" (HABERMAS, 2018, p. 429).

A vinculação entre Estado de direito e democracia requer que o indivíduo não lance mão de sua autonomia privada ou pública, mas que ambas sejam efetivadas e fortalecidas cada vez mais. Isso é tutelado pela mediação do direito que garante à pessoa de direito (Rechtsperson) o exercício da soberania popular e a proteção dos direitos humanos plasmados na inviolabilidade dos direitos fundamentais.

\begin{abstract}
Não há direito algum sem a autonomia privada das pessoas de direito em geral. Portanto, sem os direitos fundamentais que asseguram a autonomia privada dos cidadãos também não haveria o medium para institucionalizar juridicamente aquelas condições sob as quais os cidadãos, em papel de cidadãos políticos, pudessem fazer um uso da autonomia pública. Nesse sentido, a autonomia privada e a autonomia pública se pressupõem mutuamente, sem que os direitos humanos possam reivindicar um primado sobre a soberania popular, ou vice-versa (HABERMAS, 2018, p. 430).
\end{abstract}

Essa relação de complementaridade foi quebrada por dois paradigmas do direito: (i) o paradigma liberal do direito, e (ii) o paradigma do Estado de bem-estar social. O modelo liberal, movido pelos mecanismos de mercado e pela sociedade de consumo, deu centralidade ao direito privado, à autonomia privada, e fez com que o direito orbitasse em torno de regulações com vistas a proteger a esfera individual.

O indivíduo aqui foi reduzido, como fala Hegel em sua Filosofia do Direito (§ 190), à esfera dos carecimentos (Bedürfnisse), de modo que os interesses particulares se sobrepuseram aos universais. "A isso se vincula a expectativa normativa de que a justiça social possa ser produzida pela garantia desse status jurídico negativo, ou seja, pela delimitação de

5 Em Rawls essa é a questão central que perpassa a sua proposta de consenso sobreposto dentro de um escopo de uma concepção política e não metafísica de justiça: “como é possível que exista uma sociedade justa e estável, cujos cidadãos, livres e iguais, estejam profundamente divididos por doutrinas religiosas, filosóficas e morais conflitantes e até incomensuráveis?" (RAWLS, 2011, conferência IV).

\begin{tabular}{|l|l|l|l|l|}
\hline Qovista Dialectus & Ano 10 & n. 24 & Setembro - Dezembro 2021 & p. 67 - 78 \\
\hline
\end{tabular}


esferas de liberdade individuais" (HABERMAS, 2018, p. 431). O foco não era a questão da inclusão social, mas a proteção do indivíduo detentor do poder de compra e venda.

O modelo de bem-estar social, por sua vez, surge como crítica do paradigma anterior. A função do direito não deveria consistir em salvaguardar direitos individuais de consumidores e não poderia se restringir a normatizar relações de mercado, pois isso produziria exclusões dos não proprietários e dos não consumidores.

O modelo do Estado social se desenvolveu a partir de uma crítica bem fundamentada a esse pressuposto. A objeção é evidente: se a liberdade na 'capacidade de ter e de adquirir' deve garantir a justiça social, precisa haver a igualdade na 'capacidade jurídica'. Mas com a crescente desigualdade nas posições de poder econômico, nos montantes de riqueza e nas condições da vida social, são de fato cada vez mais violados os pressupostos fáticos para usar em igualdade de oportunidade as competências jurídicas distribuídas de modo igual (cf. HABERMAS, 2018, p. 431).

Desse modo, com vistas a sanar o déficit social do primeiro modelo, o paradigma do bem-estar social tem como objetivo central combater as desigualdades sociais mediante a necessidade de o direito coagir o Estado a criar políticas de redistribuição de renda e de riqueza e outras formas de amparo a pessoas excluídas. Há assim a emergência dos direitos sociais.

$\mathrm{O}$ ponto falho nesses dois paradigmas é que ambos contemplam apenas um aspecto da autonomia, a saber, a sua dimensão privada, obliterando a dimensão pública. O modelo liberal enfatiza os anseios egocêntricos dos indivíduos e os tutela juridicamente; o modelo de bem-estar social, apesar do enfoque ser social, centra-se na preocupação de atenuar as desigualdades materiais e as condições de subsistência díspares - o que pode gerar um “paternalismo do Estado de bem-estar social” (HABERMAS, 2018, p. 431) -, porém não dá um passo a frente no que diz respeito à promoção da autonomia pública, isto é, ao exercício da autonomia política orientada para a ação de sujeitos protagonistas em seus processos de participação na esfera pública.

[...] ambos os paradigmas do direito são igualmente comprometidos com a imagem produtivista de uma sociedade econômica capitalista e industrial, que deve funcionar de tal maneira que a expectativa da justiça social possa ser cumprida na tentativa de cada um realizar sua própria concepção de vida boa, assegurada pela autonomia privada. Ambos os lados apenas discordam sobre a questão como assegurar a autonomia privada: de modo imediato pelos direitos de liberdade ou pela concessão de direitos a benefícios sociais. Em ambos os casos se perde de vista o vínculo interno entre autonomia privada e autonomia pública (HABERMAS, 2018, p. 432).

O ponto de Habermas é que os dois paradigmas incorrem num déficit prejudicial para a complementaridade entre autonomia privada e autonomia pública, no sentido que não ultrapassam os limites do privado. Ambos fortaleceram um lado da relação que foi o Estado de 
direito acessado para o usufruto de vantagens particulares, porém deixaram de lado o outro lado da relação que foi a democracia.

Nesse sentido, a complementaridade entre Estado de direito e democracia requer a complementaridade entre autonomia privada e autonomia pública, de modo que a formação da vontade democrática e da opinião se torna imprescindível, sendo que, como dito, o direito desenvolve papel relevante na mediação desse vínculo à medida que garante normativamente o exercício tanto da autonomia privada como da autonomia pública. "A autonomia privada de cidadãos em pé de igualdade só pode ser assegurada se sua autonomia política se tornar ativa" (HABERMAS, 2018, p. 434). Sem essa mediação e sem essa complementaridade, cria-se um gap entre Estado de direito e democracia.

\section{Considerações finais}

Por fim, eu gostaria de salientar que, no escopo da Teoria Crítica, Honneth em $O$ direito da liberdade também coloca no centro de seu projeto de liberdade social e eticidade a formação da vontade democrática. Os direitos sociais são de fundamental importância, porém não são o objetivo final. Eles devem estar orientados para a garantia da autonomia política e para o exercício pleno da cidadania - isso constitui um componente forte da eticidade democrática honnethiana (Cf. HONNETH, 2015, p. 554). O ponto que Honneth não concordaria com Habermas refere-se ao protagonismo do direito.

\footnotetext{
O motor e o meio dos processos históricos de realização dos princípios da liberdade institucionalizada não é o direito, ao menos em primeiro lugar, mas as lutas sociais pela adequada compreensão desses princípios e as mudanças de comportamento daí resultantes. Por isso, a orientação das teorias da justiça contemporâneas pelo paradigma do direito também é um equívoco; é o caso de se considerar muito mais, em igual medida, a sociologia e a historiografia, já que é inerente a essas disciplinas dirigir sua atenção às mudanças do comportamento moral cotidiano (HONNETH, 2015, p. 630).
}

Mas isso é plausível; faz parte dos diferentes posicionamentos teóricos de ambos: Honneth tece suas considerações a partir da teoria do reconhecimento, Habermas mediante a teoria discursiva e colocando em evidência a função mediadora do direito entre facticidade e validade. Mas quero destacar que o direito também em Honneth é relevante no que diz respeito à juridificação de normas advindas de conquistas plasmadas nos processos sociais de luta por reconhecimento, todavia a sua ênfase é que direitos não vêm de procedimentos institucionalizados a partir do direito positivo, mas antes de tudo das lutas concretas por reconhecimento. 
A mediação do direito na institucionalização de procedimentos discursivos requerida por Habermas é de fundamental importância para, em primeira ordem, a manutenção do Estado de direito e da democracia e, em segunda ordem, para o seu vínculo. Sem esse vínculo, é comprometida a complementaridade entre soberania popular e direitos humanos, autonomia privada e autonomia pública e, desse modo, persistiria a tensão e a dicotomia entre liberdade dos antigos (comunidade - participação política) e liberdade dos modernos (indivíduo - direitos privados). Ao menos normativamente, penso que é clara a proposta de Habermas. A sua efetivação, tensões sociais, incompatibilidade de ethos, desajustes institucionais, tudo isso é uma outra questão da qual não tencionei abordar aqui.

A fim de corroborar a complementaridade a que me referi ao longo do artigo, gostaria de finalizar com a citação já mencionada a qual penso que expõe de modo claro a intenção de Habermas: "a autonomia privada de cidadãos em pé de igualdade só pode ser assegurada se sua autonomia política se tornar ativa" (HABERMAS, 2018, p. 434). Juntamente com o nexo entre soberania popular e direitos humanos, isso constitui uma das premissas fundamentais do vínculo entre Estado de direito e democracia, conforme tentei apresentar ao longo desta pesquisa.

\section{Referências}

CONSTANT, Benjamin. A liberdade dos Antigos comparada à dos Modernos. Trad. Emerson Garcia. São Paulo: Atlas, 2015.

GUEDES DE LIMA, F. Jozivan. A normatividade do direito de resistência no contratualismo moderno: Hobbes, Locke, Kant. Pensando - Revista de Filosofia. V. 9, n. 18, (2018).

GUEDES DE LIMA, F. Jozivan; DUTRA, Delamar, J. V. Democracia supranacional, cosmopolitismo e direito humanos segundo Habermas e à luz de Kant. Princípios: Revista de filosofia (UFRN). V. 27, n. 53, (2020).

HEGEL, Georg W. F. Princípios da Filosofia do Direito ou Direito Natural e Ciência Política em Compêndio. Trad. Paulo Meneses et al. Porto Alegre: Editora Fênix, 2021.

HABERMAS, Jürgen. A inclusão do outro: estudos de teoria política. Trad. Denilson Werle. São Paulo: Editora Unesp, 2018.

HABERMAS, Jürgen. Na esteira da tecnocracia: pequenos escritos políticos XII. Trad. Luiz Repa. São Paulo: Editora Unesp, 2014a.

HABERMAS, Jürgen. Mudança estrutural da esfera pública: investigações sobre uma categoria da sociedade burguesa. Trad. Denilson Werle. São Paulo: Editora Unesp, 2014b.

\begin{tabular}{|l|l|l|l|l|}
\hline Qevista Dialectus & Ano 10 & n. 24 & Setembro - Dezembro 2021 & p. 67 - 78 \\
\hline
\end{tabular}


HABERMAS, Jürgen. Sobre a legitimação pelos direitos humanos. In: Direito e legitimidade. Organizado por Jean-Christophe Merle e Luiz Moreira. São Paulo: Landy, 2003.

HABERMAS, Jürgen. Direito e democracia: entre facticidade e validade. V. 2. Trad. Flávio Siebeneichler. Rio de Janeiro: Tempo Brasileiro, 1997.

HABERMAS, Jürgen. Faktizität und Geltung: Beiträge zur Diskurstheorie des Rechts und des demokratischen Rechtsstaats. Frankfurt am Main: Suhrkamp Verlag, 1994. 4. Auflage.

HOBBES, Thomas. Leviatã ou matéria, forma e poder de uma república eclesiástica e civil. Trad. João Paulo Monteiro, Maria Beatriz Nizza da Silva, Claudia Berliner. São Paulo: Martins Fontes, 2003.

HONNETH, Axel. O direito da liberdade. Trad. Saulo Krieger. São Paulo: Martins Fontes, 2015 .

KANT, Immanuel. Princípios metafísicos da doutrina do direito. Trad. Joãosinho Beckenkamp. São Paulo: Editora WMF Martins Fontes, 2014.

LOCKE, John. Dois Tratados sobre o Governo Civil. $2^{\text {a }}$ ed. São Paulo: Martins Fontes, 2005.

MARCUSE, Herbert. Ideias sobre uma teoria crítica da sociedade. Trad. Fausto Guimarães. Rio de Janeiro: Zahar Editores, 1972.

RAWLS, John. O liberalismo político. Trad. Álvaro de Vita. São Paulo: Editora WMF Martins Fontes, 2011. 